\title{
ASESMENT UJIAN COMPRE LIVE IN SEKOLAH ALAM MAHIRA BENGKULU
}

\author{
Tomi Hidayat $^{1 *}$, Endang Sulaiman ${ }^{2)}$, asral $^{3)}$ \\ ${ }^{1,2,3)}$ Program Studi Pendidikan Biologi, Fakultas Keguruan dan Ilmu Pendidikan, Universitas \\ Muhammadiyah Bengkulu \\ *Author: tomihidayat@umb.ac.id
}

Informasi Artikel

Terima: $24 / 12 / 2020$

Revisi : 31/03/2021

Disetujui : 30/04/2021

Kata Kunci : Live in, SMA Alam Mahira

Bengkulu, Siswa

\begin{abstract}
ABSTRAK
Permasalahan yang diangkat dalam artikel ini adalah adanya siswa yang masih pasif dalam proses pembelajaran, kurangnya komunikasi antar siswa dengan siswa, siswa dengan guru, dan siswa dengan masyarakat lingkungan tempat tinggalnya. Metode pemecahannya diberikan sebuah kegiatan berupa Live In yang diterapkan pada siswa SMA Alam Mahira Bengkulu. Hasil dari kegiatan Live In ini dilakukan penilaian terhadap siswa yang telah melaksanakan kegiatan Live In tersebut. Hasil penilaian dikategorikan baik. Kesimpulan kegiatan assessment ujian compre live in berupa Secara umum, tujuan dari kegiatan ujian compre live in di SMA Alam Mahira Kota Bengkulu tercapai dengan baik. Hal ini dapat diamati adanya presentasi siswa dalam melaporkan hasil kegiatan live in sudah dipaparkan dengan lancar sesuai aktivitas real live in atau dengan kata lain tidak mengada-ada, selain itu siswa menunjukkan kemampuan dan keterampilan yang baik dalam presentasi, sehingga diharapkan dapat menerapkan kemandirian, sosial, kreatif, inovatif selama kegiatan live in dalam kehidupan sehari-hari ditengah kehidupan masyarakat.
\end{abstract}

\section{PENDAHULUAN}

Pendidikan nasional bertujuan untuk mengembangkan potensi peserta didik agar menjadi manusia yang beriman dan bertakwa kepada Tuhan Yang Maha Esa, berakhlak mulia, sehat, berilmu, cakap, kreatif, mandiri, dan menjadi warga negara yang demokratis serta bertanggungjawab. Pengembangan potensi dan kecakapan peserta didik sebagaimana dimaksud, menurut Peraturan Menteri Pendidikan dan Kebudayaan Republik Indonesia (Permendikbud) Nomor 22 Tahun 2016 tentang standar proses pendidikan dasar dan menengah, dapat diwujudkan melalui pemenuhan proses pembelajaran yang bermutu.

Proses pembelajaran diharapkan dilaksanakan untuk mengembangkan ranah sikap, pengetahuan, dan keterampilan secara bersama-sama (Shafa, 2014). Hal tersebut diartikan bahwa pembelajaran diharapkan mampu mengembangkan pribadi yang utuh sesuai tujuan pendidikan nasional. Khususnya dalam implementasi Kurikulum 2013 yang menekankan proses inkuiri dengan pendekatan scientific benar-benar dapat terjadi sehingga peserta didik mendapatkan pengalaman belajar yang bermakna (Kemdikbud, 2013).

Live-in, berasal dari kata live dan in yang terjemahan bebasnya yaitu "tinggal di", jadi pengertian program live in yakni suatu kegiatan yang dirancang agar individu atau suatu kelompok dapat berinteraksi secara langsung dengan kelompok 
masyarakat lain yang berbeda latar belakang baik sosial, ekonomi, adat, budaya maupun alam lingkungannya (Ahdavia, 2015). Peserta live in bukan hanya tinggal dengan kelompok masyarakat lain namun juga mengikuti aktifitas atau kegiatan masyarakat yang ditempatinya (Rahayu, 2017).

Program live-in dilaksanakan di pedesaan, dimana masyarakat pedesaan masih berpegang teguh pada kultur atau budaya serta adat istiadat disamping itu keindahan alam dan lingkungan yang masih terjaga dan sasaran program live in ini yaitu siswa atau pelajar, mahasiswa maupun kelompok masyarakat umum terutama yang tinggal di perkotaan (Sekar, dkk, 2018). Selain menambah pengetahuan dan pengalaman diharapkan peserta nantinya dapat mengaplikasikan apa yang telah diperoleh dari kegiatan live in di desa dalam kehidupan sehariharinya (Rahayu, 2017).

SMA Alam Mahira Bengkulu yang beralamat di Jl. Kinibalu VI Kebun Tebeng Kota Bengkulu ini melaksanakan program live in di desa Mangkurajo Lebong Selatan, mulai 629 September 2020. Kegiatan kali ini diikuti oleh 16 siswa dan didampingi oleh Kepala Sekolah dan Guru yang berjumlah 5 orang.

\section{METODE KEGIATAN}

A. Pelaksana Kegiatan

Pelaksana kegiatan ini adalah pihak SMA Alam Mahira Bengkulu melalui Kegiatan Live In Tahun Pelajaran 2020/2021 bekerjasama dengan tim pengabdian dosen Univesitas Muhammadiyah Bengkulu sebagai pelaksana tim penilai ujian compre live in siswa SMA Alam Mahira Bengkulu.

B. Biaya

Biaya kegiatan ini berasal dari SMA Alam Mahira Bengkulu tahun 2020 melalui kegiatan Live In bekerjasama dengan tim pengabdian dosen UM Bengkulu sebagai pelaksana tim penilai ujian compre live in siswa SMA Alam Mahira Bengkulu.

C. Waktu dan Tempat Pelaksanaan

Kegiatan ini dilaksanakan di Kota Bengkulu dengan durasi program pendampingan 3 (tiga) hari atau ekuevalen dengan 12 jam pengabdian. Deskripsi waktu dan tempat kegiatan:

\begin{tabular}{|c|c|c|}
\hline $\begin{array}{l}\text { KEGIATAN } \\
\text { KOORDINASI }\end{array}$ & KEGIATAN LIVE IN & $\begin{array}{l}\text { KEGIATAN UJIAN } \\
\text { COMPRE LIVE IN }\end{array}$ \\
\hline Sabtu, 17 Oktober 2020 & 6-29 September 2020 & 1. Senin, 19 Oktober 2020 \\
\hline Pukul $09.00-11.00 \mathrm{WIB}$ & Pukul 08.00 - 17.00 WIB & 2. Selasa, 20 Oktober 2020 \\
\hline $\begin{array}{l}\text { SMA Alam Mahira Kota } \\
\text { Bengkulu }\end{array}$ & $\begin{array}{l}\text { Desa Mangkurajo Lebong } \\
\text { Selatan Provinsi Bengkulu }\end{array}$ & 3. Rabu, 21 Oktober 2020 \\
\hline \multirow[t]{3}{*}{$\begin{array}{l}\text { Jl. Kinibalu VI Kebun } \\
\text { Tebeng Kota Bengkulu, } \\
\text { Bengkulu. }\end{array}$} & & Pukul 08.00 - 12.00 WIB \\
\hline & & $\begin{array}{l}\text { SMA Alam Mahira Kota } \\
\text { Bengkulu }\end{array}$ \\
\hline & & $\begin{array}{l}\text { Jl. Kinibalu VI Kebun Tebeng } \\
\text { Kota Bengkulu, Bengkulu. }\end{array}$ \\
\hline $\begin{array}{l}\text { D. Pengarah dan Penguj } \\
\text { 1. Pengarah berasal }\end{array}$ & dari & $\begin{array}{l}\text { MA Alam Mahira Bengkulu, } \\
\text { aitu Kepala Sekolah dan Guru. }\end{array}$ \\
\hline
\end{tabular}


2. Tim Penguji Eksternal berasal

sebagai berikut: dari unsur akademisi, yakni tim pengabdian dosen Universitas Muhammadiyah Bengkulu

\begin{tabular}{|c|l|l|}
\hline NO & \multicolumn{1}{|c|}{ NAMA } & \multicolumn{1}{c|}{ INSTANSI } \\
\hline 1 & Dr. Tomi Hidayat, M.Pd. & Universitas Muhammadiyah Bengkulu \\
\hline 2 & Drs.Endang Sulaiman, M.Pd & Universitas Muhammadiyah Bengkulu \\
\hline 3 & Drs. Nasral, M.Pd & Universitas Muhammadiyah Bengkulu \\
\hline
\end{tabular}

E. Tata Tertib

1. Setibanya di tempat kegiatan Ujian Compre Live In di SMA Alam Mahira Bengkulu, peserta langsung ke ruangan ujian yang telah ditentukan untuk:
a. menyerahkan berkas hasil keikutsertaannya pada kegiatan Live In,
b. mengisi presensi atau daftar hadir,
c. menerima panduan dan bahan-bahan pelaksanaan kegiatan Ujian Compre Live In.

2. Biaya makanan dan minuman diluar fasilitas yang disediakan panitia, merupakan tanggungjawab peserta sendiri.

3. Peserta berpakaian rapi dalam mengikuti semua kegiatan sesuai dengan ketentuan.

4. Apabila sakit atau mendapat sesuatu halangan, mohon segera melapor kepada panitia.

5. Peserta diwajibkan mengikuti semua kegiatan sesuai dengan jadwal yang telah ditentukan panitia.

6. Peserta meminimalisir penggunaan HP baik untuk pengiriman pesan singkat, menelpon, WA, facebook, email, dsb. selama kegiatan Ujian Compre Live In berlangsung, Penggunaan HP hanya selama istirahat.

7. Produk kegiatan ini sepenuhnya milik SMA Alam
Mahira Kota Bengkulu.

\section{B. Output Kegiatan Ujian Compre Live In}

Output kegiatan Ujian Compre Live In ini antara lain sebagai berikut:

1. Nilai Ujian Compre Live In

2. Lembar hasil Asesment Ujian Compre Live In

3. Video Testimoni Tim Penguji Compre Live In

4. Foto/ gambar tentang aktivitas kegiatan Live In belajar siswa di lapangan.

3. HASIL DAN PEMBAHASAN A. Deskripsi Pelaksanaan Kegiatan Pelaksanaan Hari ke-1 (Senin, 19 Oktoer 2020)

Kegiatan Live In merupakan salah satu program pengembangan dari kesiswaan SMA Alam Mahira Bengkulu, dimana para siswa (peserta) dititipkan kepada keluarga-keluarga di daerah pedesaan yang nantinya akan menjadi orangtua asuh mereka selama kegiatan berlangsung. Selama hidup bersama dengan keluarga baru (orang tua asuh), mereka diajak untuk belajar hidup mandiri dan bersosialisasi dengan keluarga dan masyarakat setempat, merasakan keprihatinan dan kegembiraan keluarga dan masyarakat pedesaan dengan kemampuannya masing-masing dan mencoba merefleksikan dengan pengalaman hidupnya sehingga mampu menemukan nilai-nilai baru yang bisa menjadikan mereka menjadi individu yang baik. 
Selain itu, siswa dilatih pula untuk bisa menemukan nilai-nilai kehidupan yang melekat dalam keluarga di pedesaan yang mereka tempati, terbuka hatinya setelah melihat fakta bahwa masih banyak saudara-saudara yang tidak hidup seberuntung mereka saat ini, sehingga muncul kepekaan dan kepedulian terhadap sesama dan mensyukuri hidup yang telah Allah berikan selama ini, menemukan nilai hidup dan mampu menentukan sikap serta semangat hidup baru dalam rangka membenahi dan mengembangkan diri, sehingga dapat membuka cakrawala baru bagi siswa untuk lebih berjuang dan berbagi/berbelarasa kepada sesama. Itulah sebabnya SMA Alam Mahira Bengkulu memilih di Desa Mangkurajo, Lebong Selatan, Bengkulu sebagai lokasi yang tepat, yaitu sebuah wilayah yang sungguh jauh berbeda dengan tempat dimana para siswa hidup selama ini, dengan harapan supaya mereka benar-benar mampu merefleksikan dengan pengalaman hidupnya sehingga mampu menemukan nilai-nilai baru yang bisa menjadikan pengalaman berharga. Kegiatan live in Desa Mangkurajo, Lebong Selatan, Bengkulu berlangsung pada tanggal 6-29 September 2020. Para siswa sangat antusias dengan kegiatan live in ini karena mereka bisa ikut bertani, mencari rumput untuk memberi makan hewan ternak, memasak dan berdagang untuk membantu atau sekedar meringankan pekerjaan orangtua asuh mereka masing-masing.

Hari pertama kegiatan asesment ujian compre live in diawali dengan kedatangan tim dosen penguji compre live in di SMA Alam Mahira Kota Bengkulu, yang dilanjutkan dengan koordinasi pelaksanaan kegiatan. Koordinasi kegiatan diikuti oleh pihak SMA Alam Mahira Kota Bengkulu dan Tim Dosen Universitas Muhammadiyah Bengkulu sebagai Penguji Ujian
Compre Live In serta siswa SMA Alam Mahira Kota Bengkulu. Koordinasi menyepakati tentang :

1. Teknis kegiatan selama 3 hari

2. Pembagian tugas penilaian

3. Pembagian presentasi laporan hasil Live In oleh Siswa SMA Alam Mahira Kota Bengkulu

4. Teknis Penilaian Ujian Live In yang akan dilakukan

Pelaksanaan Hari ke-2 (Selasa, 20 Oktober 2020)

Hari kedua merupakan pelaksanaan presentasi laporan hasil kegiatan Live In yang telah siswa lakukan, dilaksanakan di SMA Alam Mahira Kota Bengkulu dimulai pada pukul 08.00-12 WIB. Tim Penilai Eksternal dan Internal melakukan penilaian dan memberi masukkan dan saran kekurangan dalam kegiatan Live In oleh siswa SMA Alam Mahira Kota Bengkulu.

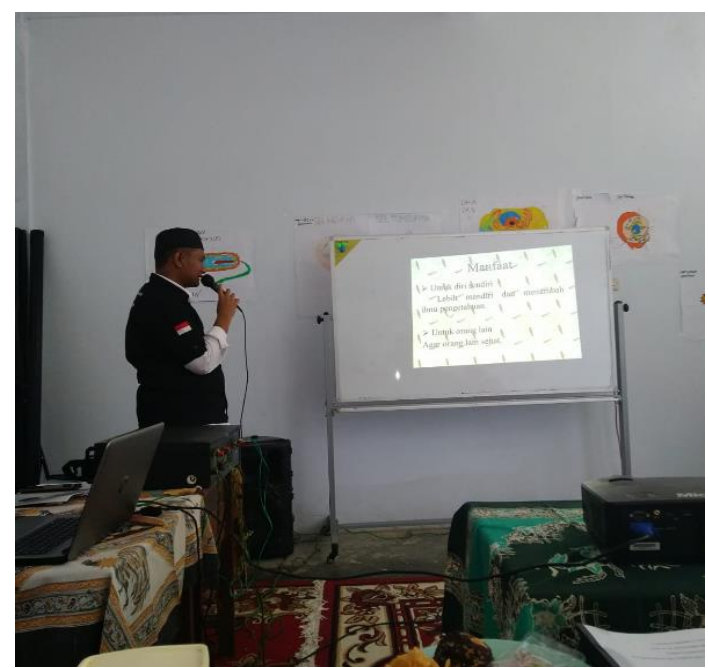

\section{Gambar 1. Siswa melakukan presentasi hasil Live In}

\section{Pelaksanaan hari ke-3 (Rabu, 21} Oktober 2020)

Hari kedua merupakan lanjutan pelaksanaan presentasi laporan hasil kegiatan Live In yang telah siswa lakukan, dilaksanakan di SMA Alam 
Mahira Kota Bengkulu dimulai pada pukul 08.00-12 WIB. Tim Penilai Eksternal dan Internal melakukan penilaian dan memberi masukkan dan saran kekurangan dalam kegiatan Live In oleh siswa SMA Alam Mahira Kota Bengkulu.

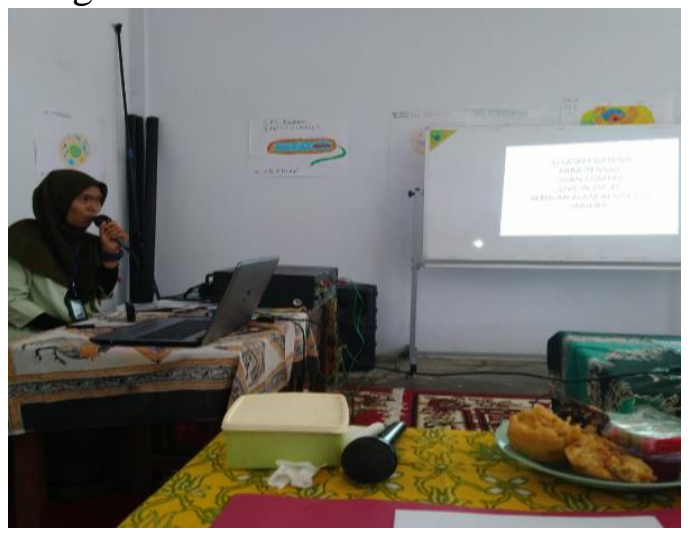

Gambar 2. Siswa melakukan presentasi hasil Live In

Berdasarkan hasil ujian compre live in diperoleh skor tertinggi peserta sebesar 92 sebanyak 3 orang sedangkan untuk skor terendah adalah 72 dengan sebanyak 13 orang.

\section{B. Dukungan}

Keberhasilan kegiatan ujian compre live in siswa SMA Alam Mahira Kota Bengkulu berkat adanya dukungan dari:

1. Peran serta peserta siswa dan pihak sekolah, yaitu guru, staf dan kepala sekolah yang sangat antusias dalam mengikuti seluruh rangkaian kegiatan ujian compre live in di SMA Alam Mahira Kota Bengkulu. Antusiasme peserta ditandai dengan frekuensi kehadiran yang tinggi, disiplin dalam mengikuti kegiatan ujian compre live in di SMA Alam Mahira Kota Bengkulu;

2. Dukungan tim penguji eksternal dari Universitas Muhammadiyah Bengkulu dengan kompetensi dalam bidang assessment perkembangan peserta didik terkait dengan kegiatan Live In yang telah dilakukan siswa.

3. Dukungan sarana dan prasarana yang disediakan oleh pihak SMA Alam Mahira Kota Bengkulu yang cukup baik, sehingga peserta dan tim dosen penguji ujian compre live in merasa nyaman dalam mengikuti setiap kegiatan.

\section{PENUTUP}

\section{A. Kesimpulan}

Secara umum, tujuan dari kegiatan ujian compre live in di SMA Alam Mahira Kota Bengkulu tercapai dengan baik. Hal ini dapat diamati adanya presentasi siswa dalam melaporkan hasil kegiatan live in sudah dipaparkan dengan lancar sesuai aktivitas real live in atau dengan kata lain tidak mengada-ada, selain itu siswa menunjukkan kemampuan dan keterampilan yang baik dalam presentasi, sehingga diharapkan dapat menerapkan di kemandirian, sosial, kreatif, inovatif selama kegiatan live in dalam kehidupan sehari-hari ditengah kehidupan masyarakat.

\section{B. Saran}

Agar pelaksanaan kegiatan ujian compre live in yang sama pada masa yang akan datang dapat diselenggarakan dengan lebih baik, disarankan hal-hal sebagai berikut:

1. Pemilihan siswa kegiatan live in tetap melibatkan penguji eksternal dari pihak universitas, untuk lebih berkompeten dalam bidangnya.

2. Koordinasi dari pihak sekolah ke pihak kampus untuk lebih intens, sehingga terjalin kolaborasi 
dalam bidang pengabdian kepada masyarakat.

\section{DAFTAR PUSTAKA}

Ahdavia, Ikrima. 2015. Laporan Perjalanan Kegiatan Live In Cinangneng Bogor Barat. Bogor.

Kemdikbud. (2013). Materi Pelatihan Guru Implementasi Kurikulum 2013. Jakarta: Kemdikbud.

Peraturan Menteri Pendidikan dan Kebudayaan Republik Indonesia (Permendikbud) Nomor 22 Tahun 2016 tentang standar proses pendidikan dasar dan menengah, dapat diwujudkan melalui pemenuhan proses pembelajaran yang bermutu.

Rahayu, Titi. 2017. Pendidika Karakter Berbasis Live In Di Sekolah Menengah Atas Atisa Dipamkara. Artikel Skripsi: Sekolah Tinggi Agama Buddha Negeri Sriwijaya Tangerang Banten.

Sekar, A., Herawati, A., Maharani, C., Bela, S.K., Putri. N. Y. 2018. Laporan Hasil Live In Exposure In The Poor Di Dusun Ngesong Desa Manyaran Kecamatan Banyakan Kabupaten Kediri. Laporan Hasil: SMP KAtolik Santa Maria Kediri.

Shafa. 2014. Karakteristik Proses Pembelajaran Kurikulum 2013. Jurnal Dinamika Ilmu. Volume 14 Nomor 1. 